\title{
Construction of Mass Balances of Cocaine in Batch Studies for the Sewage Treatment Works
}

\author{
*MUSTAPHA, AO; ADEYEMI, DA \\ ${ }^{* l}$ Department of Chemical, Geological \& Physical Sciences, College of Pure and Applied Sciences. Kwara State University Malete, PMB \\ 1530, Ilorin, Kwara State, Nigeria \\ ${ }^{2}$ Department of Science Technology, School of Applied Sciences and Technology. Federal Polytechnic Offa, PMB 420, Kwara State, \\ Nigeria \\ *Corresponding Author Email: aliru.mustapha@kwasu.edu.ng; Other Author Email: adeyemi.adefunke02@gmail.com
}

\begin{abstract}
The desired approach at safeguarding the environment both in control and effective monitoring of chemical discharges is the use of mass balances to account for inflow/outflow of pollutants. Whereas the previous studies were based on several assumptions, the batch studies enabled the construction of mass balances for the Sewage Treatment Work (STWs) using the removal rate data. This study, for the first time measures the rates of removal of cocaine in an STW, and the calculated mass balances were obtained from the removal rate data that were generated. The result of cocaine initial influent of $50 \mathrm{mg} \mathrm{L}-1$ after after 2 hour hydraulic retention times (HRT) produced the final effluents of $110 \mathrm{mg} \mathrm{L}-1$. Projected influent concentrations of cocaine $(14,471 \mathrm{ng} \mathrm{L}-1)$ were derived from back-calculation from final effluent concentrations. A useful tool that accounts for the mass-flow of trace drugs in the aquatic environment with minimal errors often due to sampling logistics and desludging process has been provided in this model of mass balance calculations in STWs.
\end{abstract}

\section{DOI: https://dx.doi.org/10.4314/jasem.v24i6.24}

Copyright: Copyright (C) 2020 Mustapha and Adeyemi. This is an open access article distributed under the Creative Commons Attribution License (CCL), which permits unrestricted use, distribution, and reproduction in any medium, provided the original work is properly cited.

Dates: Received: 20 April 2020; Revised: 24 May 2020; Accepted: 25 June 2020

Keywords: removal rate, effluent, influent, mass balance, sewage treatment work, cocaine

The inherent assumptions by most authors in the literature with the mass balances of organic pollutants which include heavy metals in the sewage treatment works (STWs) have been highlighted (Liu et al., 2017; Manitcharoen and Pinpunchat, 2020: SulejSuchomska et al., 2020: Yang et al., 2017; Zuccato et al., 2008a). The Zuccato et al (2015) estimated the cocaine levels in wastewaters where he first approximated the loads of parent cocaine from the concentration of benzoylecgonine (BZE), a main metabolite of cocaine in effluent wastewater. Certain assumptions in their approach were: (i) excreted BZE was assumed to be $45 \%$ of ingested cocaine dose (ii) the sewage system has no wastewater leakage (iii) no 'dumping' of large quantities of BZE or accidental discharge and (iv) the human urination were only main source of cocaine and metabolites used in back calculation of the major product. In calculating the cocaine load (g day-1), the molar fraction, concentration of flow rate of cocaine and BZE (ng L1 ), and molar mass ratio were all estimated. This approach was used to estimate the community consumption of cocaine, cannabinoids and opiates per day/1000 people. Zuccato et al (2015) used another approach and assumed that stability of cocaine in aqueous media was greater than its metabolites, BZE and used $10 \%$ as a percentage of parent cocaine excreted to estimate the level of cocaine consumed.
The apparent discrepancies in the literature (Kumura et al., 2007) differ on the actual amount (\%) of excreted benzoylecgonine (BZE) and cocaine from cocaine dose were not clear as many batch data were not made available in the assessment quality, therefore more information were needed to address the discrepancies to account for the overall mass flow of drugs. Kumura et al. (2007) used simple mass balance calculations in estimation of acidic pharmaceuticals in municipal wastewaters, but the introduction of high errors due to desludging process and sampling logistics often create problems in the methods and methodology of the mass balances making its reporting to vary considerably. The errors were introduced into the estimation of some pharmaceuticals in the flow of activated sludge in England when the settled sewage was allowed to mix with the returned activated sludge (RAS) and this introduced bias (Jone et al., 2007). After a review of other previous approaches (Baena-Nogueras et al., 2017; Madikizela et al., 2017) with apparent inability to assess the quality tools in analyzing the mass balance of organic compounds in sewage works. This current work at solving the discrepancies in calculating the mass balances of pollutants in the literature have been achieved by offering alternative and quality technique in sewage treatment works.

\section{MATERIALS AND METHODS}


Materials and Chemicals: Cocaine, benzoylecgonine, Analar grade $\mathrm{HCl}, \mathrm{NH}_{4} \mathrm{OH}$ and $\mathrm{MeOH}$ were purchased from Sigma Aldrich (Gillingham Dorset, UK) and LGC standards (Teddington Middlesex, UK). They were used for $\mathrm{pH}$ scale adjustment and sample preparations. A derivatizing agent, N, O, bis (trimethylsilyl) trifluoroacetamide (BSTFA with 1\% trimethylchlorosilane, TMCS) was purchased from Cerrilliant (Round Rock, TX, USA). The choice of BSTFA as a silylating agent for derivatizaion is due to its faster reaction and volatility of its by-products. Pyridine was also purchased from Aldich and was used to provide appropriate derivatization reaction medium. Reagent water was from a Millipore milliQ water purification system (ELGA labwater, UK). Oasis HLB ${ }^{\circledR}$ sorbent in a $47 \mathrm{~mm}$ SPE disc format and disc holder were purchased from Waters (Elstree Herts, UK). A Phenomenex SPE Vacuum Manifold (Macclesfield Cheshire, UK) were used for loading and elution of samples with appropriate solvent mixtures.

Batch Studies Experiment: For batch studies, $250 \mathrm{ml}$ of each unfiltered sludge samples obtained from a Municipal Sewage Treatment Works were measured in a conical flask and spiked with $12.5 \mathrm{mg}$ of standard drug (Sigma Aldrich analar grade: cocaine). Samples of drugs were taken for determination at $15 \mathrm{~min}$ intervals for over a period of $3 \mathrm{~h}$, The final analysis was carried out using a modified gas chromatographicmass spectrometry analytical method with an Agilent
6890 GC coupled to Agilent 5975 inert XL mass selector detector. With sample injection in splitless mode, the analyte separation was achieved with the temperature programming: $50^{\circ} \mathrm{C}$ (hold $2 \mathrm{~min}$ ), rise to $300^{\circ} \mathrm{C}$ at $10^{\circ} \mathrm{C} \mathrm{min}-1$ and then held at $300^{\circ} \mathrm{C}$ for $3 \mathrm{~min}$.

Mass balance calculation of cocaine: The removal data $(\%)$ in form of degradation and adsorption to solids from the sludge experiment were shown in Table 1 with the processing (sampling) sewage units of primary sludge (PS), submerged aerated filter-1 (SAF-1), mixed submerged aerated filter (MSAF) and humus sludge (HS). After 2 HRT, back calculation data in Table 4 completed the construction of the cocaine mass balances.

\section{RESULTS AND DISCUSSION}

Investigations on the degradation processes as well as the extent of transformations of cocaine in producing different chemical metabolites were studied (Yang et al., 2017). The pathways of microbial degradation of selected acidic pharmaceuticals and their occurrence in municipal wastewater treated by a membrane bioreactor have earlier been reported (Liu et al., 2017). To further understand the behaviour of cocaine in sewage plants, studies of mass balances from the biodegradation of cocaine residual of benzoylecgonine confirmed the effects of biodegradations. (BaenaNogueras et al., 2017; Madikizela et al., 2017)..

Table 1: Batch data for mass balance calculation of cocaine in STW processing units.

\begin{tabular}{|c|c|c|c|c|c|c|c|c|c|c|c|}
\hline \multirow[b]{2}{*}{$\begin{array}{l}\text { Time } \\
(\mathrm{min}) \\
\end{array}$} & \multicolumn{4}{|c|}{$\begin{array}{l}\text { Removal rate (\%) from each } \\
\text { STW units }\end{array}$} & \multicolumn{5}{|c|}{$\begin{array}{l}\text { Cocaine partition in aqueous and solid phases } \\
(\mu \mathrm{g} \text { in } 250 \mathrm{~mL})\end{array}$} & \multirow[b]{2}{*}{$\begin{array}{l}\text { Mass } \\
\text { Balance }\end{array}$} & \multirow{2}{*}{$\begin{array}{l}\text { Final } \\
\text { Effluen } \\
\left(\mu g \mathrm{~L}^{-1}\right)\end{array}$} \\
\hline & PS & SAF & MSAF & HS & PS & SAF & MSAF & HS & $\begin{array}{l}\text { Total } \\
\text { degraded } \\
\& \text { sorbed } \\
\end{array}$ & & \\
\hline \multirow[t]{2}{*}{15} & 4.7 & 37.0 & 5.1 & 19.0 & 587.50 & 217.38 & 11.09 & 2.11 & & 12500 & 8.43 \\
\hline & 95.3 & 63.0 & 94.9 & $\underline{81.0}$ & 11912.50 & 370.13 & 206.29 & 8.98 & 12497.89 & & \\
\hline \multirow[t]{2}{*}{30} & $\overline{3.5}$ & $\overline{33.6}$ & 4.1 & $\overline{16.5}$ & 437.50 & $\overline{147.00}$ & 6.03 & $\overline{0.99}$ & & 12500 & 3.98 \\
\hline & 96.5 & 66.4 & 95.9 & $\underline{83.5}$ & 12062.50 & 290.50 & 140.97 & $\underline{5.03}$ & 12499.01 & & \\
\hline \multirow[t]{2}{*}{45} & 3.5 & $\overline{26.9}$ & 3.6 & 14.8 & 437.50 & 117.69 & 4.24 & 0.63 & & 12500 & 2.51 \\
\hline & $\underline{96.5}$ & 73.1 & $\underline{96.4}$ & $\underline{85.2}$ & 12062.50 & $\underline{319.81}$ & 113.45 & $\underline{3.61}$ & 12499.37 & & \\
\hline \multirow[t]{2}{*}{60} & $\overline{3.4}$ & $\overline{27.2}$ & $\overline{1.8}$ & $\overline{16.8}$ & 425.00 & $\overline{115.60}$ & 2.08 & $\overline{0.35}$ & & 12500 & 1.40 \\
\hline & 96.6 & 72.8 & 98.2 & $\underline{83.2}$ & 12075.00 & 309.40 & 113.52 & 1.73 & 12499.65 & & \\
\hline \multirow[t]{2}{*}{75} & 3.0 & $\overline{24.0}$ & 1.4 & $\overline{15.1}$ & 375.00 & 90.00 & 1.26 & $\overline{0.19}$ & & 12500 & 0.76 \\
\hline & 97.0 & 76.0 & 98.6 & 84.9 & 12125.00 & 285.00 & 88.74 & 1.07 & 12499.81 & & \\
\hline \multirow[t]{2}{*}{90} & 1.8 & $\overline{20.4}$ & 1.3 & 12.5 & 225.00 & 45.90 & $\overline{0.60}$ & 0.07 & & 12500 & 0.30 \\
\hline & $\underline{98.2}$ & 79.2 & $\underline{98.7}$ & $\underline{87.5}$ & $\underline{12275.00}$ & $\underline{179.10}$ & $\underline{45.30}$ & $\underline{0.52}$ & 12499.93 & & \\
\hline \multirow[t]{2}{*}{105} & 1.8 & 13.8 & 1.2 & 10.7 & 225.00 & 31.05 & 0.37 & 0.04 & & 12500 & 0.16 \\
\hline & $\underline{98.2}$ & $\underline{86.2}$ & $\underline{98.8}$ & $\underline{89.3}$ & 12275.00 & $\underline{193.95}$ & $\underline{30.68}$ & $\underline{0.33}$ & 12499.96 & & \\
\hline \multirow[t]{2}{*}{120} & 1.6 & $\overline{11.3}$ & 1.3 & 9.0 & 200.00 & 22.60 & 0.29 & $\overline{0.03}$ & & 12500 & 0.11 \\
\hline & 98.4 & 88.7 & 98.7 & 91.0 & 12300.00 & 177.40 & 22.31 & $\underline{0.27}$ & 12499.97 & & \\
\hline \multirow[t]{2}{*}{135} & $\overline{1.3}$ & 9.2 & 0.9 & 7.9 & 162.50 & $\overline{14.95}$ & $\overline{0.13}$ & $\overline{0.01}$ & & 12500 & 0.04 \\
\hline & 98.7 & $\underline{90.8}$ & 99.1 & $\underline{92.1}$ & 12337.50 & 147.55 & 14.82 & $\underline{0.12}$ & 12499.99 & & \\
\hline \multirow[t]{2}{*}{150} & 1.0 & 5.3 & 0.6 & 5.9 & 125.00 & 6.63 & $\overline{0.04}$ & 0.00 & & 12500 & 0.01 \\
\hline & $\underline{99.0}$ & 94.7 & 99.4 & $\underline{94.1}$ & 12375.00 & $\underline{118.38}$ & $\underline{6.59}$ & $\underline{0.04}$ & 12500.00 & & \\
\hline \multirow[t]{2}{*}{165} & 0.7 & 4.0 & 0.4 & 2.7 & 87.50 & 3.50 & $\overline{0.01}$ & $\overline{0.00}$ & & 12500 & 0.00 \\
\hline & $\underline{99.3}$ & $\underline{96.0}$ & 99.6 & $\underline{97.3}$ & 12412.50 & $\underline{84.00}$ & $\underline{3.49}$ & $\underline{0.01}$ & 12500.00 & & \\
\hline \multirow[t]{2}{*}{180} & $\overline{0.4}$ & 2.4 & $\overline{0.2}$ & 1.4 & $\overline{50.00}$ & 1.20 & $\overline{0.00}$ & $\overline{0.00}$ & & 12500 & 0.00 \\
\hline & 99.6 & 97.6 & 99.8 & 98.6 & 12450.00 & 48.80 & 1.20 & 0.00 & 12500.00 & & \\
\hline
\end{tabular}

In the STW, the initial influent concentration of cocaine goes through the processing units of primary (PS), submerged aerated filter-1 (SAF-1), mixed submerged aerated filter (MSAF) and humus sludge (HS) as shown for every $15 \mathrm{~min}$ timescale for a total of $2-3$ hour HRT. The concentration of cocaine with 
percent dissolved in aqueous phase moves through the processing units and the corresponding removal rates are measured from the successful units to the final effluent. The removal data in form of degradation and adsorption to solids from the sludge experiment were shown in Table 1 and 2. In the last column, the final effluent concentrations $\left(\mu \mathrm{g} \mathrm{L}^{-1}\right)$ were multiplied by 4 to make $50 \mathrm{mg} \mathrm{L}^{-1}$ (12500 $\mu \mathrm{g}$ was in $250 \mathrm{~mL}$ flask). The mass balance back-calculation in reversed order at different STW units is in Table 2. The cocaine batch data were put in back-calculations to estimate cocaine influent concentrations as presented in Table 3

Table 2: Back calculation of mass balance in reversed order at different STW units.

\begin{tabular}{|c|c|c|c|c|c|c|c|c|c|}
\hline \multirow{2}{*}{$\begin{array}{l}\text { Time } \\
(\min )\end{array}$} & \multicolumn{4}{|c|}{$\begin{array}{l}\text { Removal rate (\%) from each STW } \\
\text { units }\end{array}$} & \multicolumn{4}{|c|}{$\begin{array}{l}\text { Cocaine partition in aqueous and solid phases } \\
(\mu \mathrm{g} \text { in } 250 \mathrm{~mL})\end{array}$} & \multirow[b]{2}{*}{$\begin{array}{l}\text { Total degraded } \& \\
\text { sorbed }\end{array}$} \\
\hline & HS & MSAF & SAF & PS & HS & MSAF & SAF & PS & \\
\hline \multirow[t]{2}{*}{15} & 19.0 & 5.1 & 37.0 & 4.7 & 2.11 & 11.09 & 217.38 & 587.50 & 12497.89 \\
\hline & $\underline{81.0}$ & $\underline{94.1}$ & $\underline{63.0}$ & 95.3 & $\underline{8.98}$ & 206.29 & $\underline{370.13}$ & $\underline{11912.50}$ & \\
\hline \multirow[t]{2}{*}{30} & $\overline{16.5}$ & 4.1 & $\overline{33.6}$ & 3.5 & $\overline{0.99}$ & 6.03 & $\overline{147.00}$ & 437.50 & 12499.01 \\
\hline & $\underline{83.5}$ & $\underline{95.9}$ & $\underline{66.4}$ & $\underline{96.5}$ & $\underline{5.03}$ & $\underline{140.97}$ & $\underline{290.50}$ & $\underline{12062.50}$ & \\
\hline \multirow[t]{2}{*}{45} & $\overline{14.8}$ & $\overline{3.6}$ & $\overline{26.9}$ & $\overline{3.5}$ & $\overline{0.63}$ & 4.24 & $\overline{117.69}$ & 437.50 & 12499.37 \\
\hline & $\underline{85.2}$ & $\underline{96.4}$ & $\underline{73.1}$ & $\underline{96.5}$ & $\underline{3.61}$ & $\underline{113.45}$ & $\underline{319.81}$ & $\underline{12062.50}$ & \\
\hline \multirow[t]{2}{*}{60} & $\overline{16.8}$ & 1.8 & $\overline{27.2}$ & $\overline{3.4}$ & $\overline{0.35}$ & $\overline{2.08}$ & $\overline{115.60}$ & 425.00 & 12499.65 \\
\hline & $\underline{83.2}$ & $\underline{98.2}$ & $\underline{72.8}$ & $\underline{96.6}$ & $\underline{1.73}$ & 113.52 & $\underline{309.40}$ & 12075.00 & \\
\hline \multirow[t]{2}{*}{75} & $\overline{15.1}$ & 1.4 & $\overline{24.0}$ & 3.0 & $\overline{0.19}$ & 1.26 & 90.00 & 375.00 & 12499.81 \\
\hline & $\underline{84.9}$ & $\underline{98.6}$ & $\underline{76.0}$ & 97.0 & $\underline{1.07}$ & $\underline{88.74}$ & $\underline{285.00}$ & $\underline{12125.00}$ & \\
\hline \multirow[t]{2}{*}{90} & $\overline{12.5}$ & 1.3 & $\overline{20.4}$ & 1.8 & $\overline{0.07}$ & 0.60 & 45.90 & 225.00 & 12499.93 \\
\hline & $\underline{87.5}$ & $\underline{98.7}$ & $\underline{79.2}$ & $\underline{98.2}$ & $\underline{0.52}$ & $\underline{45.30}$ & $\underline{179.10}$ & $\underline{12275.00}$ & \\
\hline \multirow[t]{2}{*}{105} & 10.7 & 1.2 & 13.8 & 1.8 & 0.04 & 0.37 & 31.05 & 225.00 & 12499.96 \\
\hline & $\underline{89.3}$ & $\underline{98.8}$ & $\underline{86.2}$ & $\underline{98.2}$ & $\underline{0.33}$ & $\underline{30.68}$ & $\underline{193.95}$ & 12275.00 & \\
\hline \multirow[t]{2}{*}{120} & 9.0 & 1.3 & 11.3 & 1.6 & 0.03 & 0.29 & 25.64 & 226.90 & 12499.92 \\
\hline & $\underline{91.0}$ & $\underline{98.7}$ & $\underline{88.7}$ & 98.4 & $\underline{0.27}$ & 25.34 & $\underline{201.26}$ & $\underline{12273.08}$ & \\
\hline \multirow[t]{2}{*}{135} & 7.9 & 0.9 & 9.2 & 1.3 & $\overline{0.01}$ & 0.13 & 14.95 & 162.50 & 12499.99 \\
\hline & $\underline{92.1}$ & 99.1 & $\underline{90.8}$ & 98.7 & $\underline{0.12}$ & 14.82 & $\underline{147.55}$ & 12337.50 & \\
\hline \multirow[t]{2}{*}{150} & 5.9 & 0.6 & 5.3 & 1.0 & $\overline{0.00}$ & 0.04 & 6.63 & 125.00 & 12500.00 \\
\hline & $\underline{94.1}$ & $\underline{99.4}$ & $\underline{94.7}$ & 99.0 & $\underline{0.04}$ & $\underline{6.59}$ & $\underline{118.38}$ & $\underline{12375.00}$ & \\
\hline \multirow[t]{2}{*}{165} & 2.7 & 0.4 & 4.0 & 0.7 & $\overline{0.00}$ & $\overline{0.01}$ & 3.50 & 87.50 & 12500.00 \\
\hline & $\underline{97.3}$ & $\underline{99.6}$ & $\underline{96.0}$ & 99.3 & $\underline{0.01}$ & $\underline{3.49}$ & $\underline{84.00}$ & 12412.50 & \\
\hline \multirow[t]{2}{*}{180} & 1.4 & 0.2 & 2.4 & 0.4 & $\overline{0.00}$ & $\overline{0.00}$ & 1.20 & 50.00 & 12500.00 \\
\hline & 98.6 & 99.8 & 97.6 & 99.6 & $\underline{0.00}$ & 1.20 & 48.80 & 12450.00 & 12497.89 \\
\hline
\end{tabular}

Table 3: Effluents concentration of cocaine to estimate influent concentration.

\begin{tabular}{|c|c|c|c|c|c|c|c|c|c|}
\hline & \multicolumn{4}{|c|}{$\begin{array}{l}\text { Analytes (\%) in aqueous } \\
\text { phase of each STW units. }\end{array}$} & \multicolumn{4}{|c|}{$\begin{array}{l}\text { Concentration of analytes } \\
\left(\text { ug } L^{-1}\right) \text { in STW units. }\end{array}$} & \multirow{2}{*}{$\begin{array}{l}\text { Estimated } \\
\text { influent } \\
\left(\mu \mathrm{g} \mathrm{L}^{-1}\right)\end{array}$} \\
\hline & HS & MSAF & SAF & PS & HS & MSAF & SAF & PS & \\
\hline$\overline{\text { Analyte }}$ & 9.0 & 1.3 & 11.3 & 1.6 & 1.9 & 21.1 & 1623.9 & 14371.1 & 14.3 \\
\hline $\mathrm{COC}$ & 91.0 & 98.7 & 88.7 & 98.4 & 19.2 & 1602.8 & 12747.2 & & \\
\hline
\end{tabular}

The equation for the $\%$ removal rate:

$$
\% \text { Removal }=100\left[\frac{\left(D_{o}-D_{a q}\right)}{D_{0}}\right]
$$

Where Do = initial drug concentration, Daq = final drug concentration in aqueous phase

Back-calculation assessment ensures that all the aggregate masses through the STW mass-flow must equal to the original total concentration $(12.5 \mathrm{mg}$ in $250 \mathrm{~mL}$ ).

[Dissolved drug] $=$ conc. of drug in effluent of each unit $\div(\%$ removal rate $)$.

First HS column: $=$ Dissolved rate $=1.9 \div 9.0 \%(0.09)$ $=21.1 \mathrm{ng}$ (dissolved cocaine goes to MSAF) $\rightarrow 91.0 \%$ (19.2 $\mathrm{ng}$ removed by sorption/degradation)
Second MSAF column $:$ Dissolved rate $=21.1 \mathrm{ng} \div 1.3 \%$ $(0.013)=1623.9 \mathrm{ng}($ dissolved cocaine goes to SAF$1) \rightarrow 98.7 \% \quad(1602.8 \quad \mathrm{ng}$ removed by sorption/degradation)

Third SAF column: Dissolved rate $=1623.9 \div 0.113$ $\mathrm{ng}=14371.1 \mathrm{ng}$ (dissolved cocaine goes to PS) $\rightarrow$ $88.7 \%$ (12747.2 ng removed by sorption/degradation)

Fourth PS column: Dissolved rate $=14371.1 \mathrm{ng}$ (influent) $=98.4 \% \quad(883882.7 \mathrm{ng}$ removed by sorption/degradation).

Comparing the projected back calculated influent cocaine concentration (14371.1 ng L- ${ }^{1}$ ) with data of the effluents cocaine concentrations obtained from different sewage works as shown in Table 4. In clear and simple steps, the removal rates were generated and used in the mass balance calculation of excreted cocaine using simple steps that were demonstrated in the current approach. 
Table 4: Comparing literature influent measurements of drugs

\begin{tabular}{llll}
\hline \multirow{3}{*}{ Avalutes } & \multicolumn{2}{l}{$\begin{array}{l}\text { Influent measurements of cocaine from other } \\
\text { places }\end{array}$} & $\begin{array}{l}\text { Calculated influent } \\
\text { concentration } \\
\left(\mu \mathrm{L}^{-1}\right)\end{array}$ \\
\cline { 2 - 3 } Cocaine & Matrix & Measured Influent $\left(\mathrm{ng} \mathrm{L}^{-1}\right)$ & \\
\cline { 2 - 3 } & $5 \mathrm{STPs}$, Spain & 225.0 & 14.3 \\
& $5 \mathrm{STPs}$, Belgium & $22-678$ & \\
& $37 \mathrm{STPs}$, Belgium & $32-753$ & \\
& $5 \mathrm{STPs}$, Ireland, UK & $489 \pm 117$ \\
& Eastem Spain & $370-1000.24$ \\
\hline
\end{tabular}

In activated sludge, viable and diverse bacterial population is maintained when the biological sludge is re-cycled from settling tank back to the aeration tank to produce high quality effluent, reduced biomass, maximised conversion of substrate and less production of waste sludge (Sulej-Suchomska et al., 2020). The oxidation of organic matter in a biological aerobic process generates carbon dioxide and water with the new but reduced biomass and dissolved residual organic matter in the effluent. Solutions of pollution concentration with uniformly and exponentially increasing forms of sources confirmed a recent attempt at solving water quality problems of pollution using a mathematical model (Manitcharoen and Pinpunchat, 2020).

Conclusion: The literature issues of the sampling supplying, desludging and apparent variations on the particular proportion of excreted cocaine and BZE from cocaine dose had been exposed. The complications of assumptions typically associated with the calculations of mass balances have now been addressed. The capabilities of this experimental batch studies have shown enhancements, with some refinements, in calculating mass balances of pollutants in STWs.

\section{REFERENCES}

Baena-Nogueras, RM; González-Mazo, E; Lara-Martín, PA (2017). Degradation kinetics of pharmaceuticals and personal care products in surface waters: photolysis vs biodegradation. The Sci. of the Total Environ. 590-591:643-654.

Bijlsma. L; Sancho, JV; Pitarch, E; Ibanez, M; Hernandez, F (2009). Simultaneous ultra-highpressure liquid chromatography-tandem mass spectrometry determination of amphetamine and amphetamine-like stimulants, cocaine and its metabolites, and a cannabis metabolite in surface water and urban wastewater, $J$. of Chromatogr. A, 1216(15):3078-3089.

Jones, OAH; Voulvoulis, N; Lester, JN (2007). The occurrence and removal of selected pharmaceutical compounds in a sewage treatment works utilizing activated sludge treatment. Environ Pollute. 145(3):738-744
Kimura, K; Hara, H; Watanabe, Y (2007). Elimination of selected acidic pharmaceuticals from municipal wastewater by an activated sludge system and membrane bioreactors. Environ Sci. Technol. $41: 3708-3714$

Liu, J; Liu, Y; Dai, Z; He, L; Ma, S (2017). Structural and Quantitative Analysis of Three C-Glycosylflavones by Variable Temperature Proton Quantitative Nuclear Magnetic Resonance. J of Anal Methods in Chem. 3:1-5

Madikizela, LM; Tavengwa, NT; Chimuka, L (2017). Status of pharmaceuticals in African water bodies: Occurrence, removal and analytical methods, $J$ Environ Manage. 193:211-220.

Manitcharoen, N and Pinpunchat, B (2020). Analytical and numerical solutions of pollution concentration with uniformly and exponentially increasing forms of sources, J. of Appl. Maths. 1-9

Mustapha, AO (2013). Fate and behavior of drugs in the environment. Nottingham Trent University, UK. $\mathrm{PhD}$ Thesis at Chemistry Department.

Sulej-Suchomska, AM., Klupczynska, A., Dereziński, P., Przybyłowski, J and Kokot, ZJ (2020). Urban wastewater analysis as an effective tool for monitoring illegal drugs, including new psychoactive substances, in the Eastern European region. Sci. Rep 10:4885-4897

Yang, S; McDonald, J; Hai, FI; Price, WE; Khan, SJ; Nghiem, LD (2017). The fate of trace organic contaminants in sewage sludge during recuperative thickening anaerobic digestion. Biores. Technol. (17): 30127-30153

Zuccato, E; Castiglioni, S; Bagnati, R; Chiabrando, C; Grassi, P; Fanelli, R (2008a). Illicit drugs, a novel group of environmental contaminants, Water Res. 42 (4-5):961-968.

Zuccato, E; Chiabrando, C; Castiglioni, S; Calamari, D; Bagnati R; Schiarea, S (2015). Cocaine in surface waters: a new evidence-based tool to monitor community drug abuse, Environ. Health: a global access science source. 4:14-21 